\title{
Beta- Endorphins- A Novel Holistic Therapeutic Approach to Autoimmune Diseases
}

\author{
Shrihari TG* \\ Department of Oral medicine and oral oncology, Krishna devaraya college of dental sciences and hospital, India
}

Received: 㭗 August 21, 2018; Published: 海 August 30, 2018

*Corresponding author: Shrihari TG, Assistant professor, Department of Oral medicine and oral oncology, Krishna devaraya college of dental sciences and hospital, Bangalore-562157, Karnataka, India

\begin{abstract}
Chronic psychological stress is a main etiological factor for autoimmune disease by releasing neuropeptides activates inflammatory mediators such as IL-1 $\beta$, TNF- $\alpha$, IL-6, and COX-2. These inflammatory mediators induce NF-KB transcription factor involved in chronic inflammation, immune modulation, cellular changes, and tissue damage, augments an autoimmunity. Beta-endorphins is an abundant endorphin, natural neuropeptides synthesized and stored in the anterior pituitary gland through hypothalamus mediated by autonomic nervous system (ANS), in response to stressful conditions such as physical exercise, yoga, and meditation. Beta- endorphins involved in treatment of autoimmune diseases by reduction of stress and inflammation. This article highlights about the role of beta-endorphins on auto-immune diseases.
\end{abstract}

Keywords: HPA-Axis; NF-KB; Stress; Neuropeptides; Cortisol; ACTH; Noradrenaline

\section{Introduction}

Endorphins are endogenous morphine, neuropeptides produced from pituitary gland in response to stress and pain There are three types of endorphins $\beta$ - endorphins, enkephalins, and dynorphins binds to mu, kappa, and delta receptors located on nerves and immune cells. Beta- endorphins are abundant endorphins synthesized and stored in the anterior pituitary gland, it is a precursor of POMC (proopiomelanocortin). Endorphins are produced during yoga, meditation, intense physical exercise creates relaxed psychological state known as 'Runners high', pranayama, music therapy, love, tender, care [1-4].

\section{Chronic psychological stress and autoimmune disease}

Chronic psychological stress induced CRH (corticotropic releasing hormone) from hypothalamus activates HPA-axis through autonomic nervous system induced release of neuropeptides such as cortisol, ACTH, noradrenaline activates IL- $1 \beta$, TNF- $\alpha$, IL- 6 and COX-2 inflammatory mediators. These inflammatory mediators responsible for activation of NF-kB a key transcription factor induced inflammatory mediators such as chemokines, cytokines, growth factors, proteolytic enzymes involved in conversion of TH1 to TH2 lymphocytic teeters alteration involved in immune modulation, otherwise leads to self-tolerance and immune homeostasis, activation of mumps and growth factors such as EGF, FGF, all these changes leads to immunomodulation, cell proliferation and tissue damage results in autoimmune disease [5-8].

\section{Mechanism of actions of beta endorphins in treatment} of autoimmune disease

In the PNS, binding of $\beta$ - endorphins to the receptors on peripheral nerves results in inhibition of neurotransmitter of pain substance p leads to analgesic activity. In the CNS, instead of inhibition of substance $\mathrm{P}$ a neurotransmitter of pain, it inhibits GABA inhibitory neurotransmitter, results in activation of dopamine involved in analgesic activity, euphoric activity, cognitive development, stress buster activity, and tranquility of mind [5-10]. Beta-endorphins inhibits sympathetic neuronal activity and activating parasympathetic neuronal activity, there by inhibiting neuropeptide's such as cortisol, ACTH, noradrenaline mediated inflammatory mediators such as IL- $1 \beta$, TNF- $\alpha$, and COX2 , results in inhibition of activation of NF-KB induced expression of inflammatory mediators such as cytokines, chemokines, growth factors, and proteolytic enzymes involved in conversion of TH1 to TH2 lymphocytic type, Th17 cells involved in chronic inflammation, immune modulation, and tissue damage. Tregs (Regulatory T cells) alteration involved in immune modulation produced from TH1 cells mediated by IL-10 and TGF- $\beta$ inflammatory mediators otherwise normally involved in self-tolerance and immune homeostasis, activation of growth factors such as EGF, FGF, VEGF involved in cell proliferation and angiogenesis. Proteolytic enzymes such as matrix metalloproteases (Mmp's) leads to tissue damage all these changes leads to autoimmune disease [5-8].

\section{Conclusion}

Endorphins are endogenous morphine. Beta- endorphin is a type of endorphin synthesized and stored in the anterior pituitary gland in response to certain stress full conditions of human body. It has a natural stress buster, analgesic, euphoric, immune-stimulatory activity and anti-inflammatory activity to combat against autoimmune diseases without any adverse effects. Beta endorphins acts as a natural holistic therapeutic approach to autoimmune diseases. 


\section{References}

1. Ljudmila stojanovich (2010) Stress and autoimmunity. Autoimmunity reviews 9: 271-76.

2. Stojanovich L, Marisavijevich D (2008) Stress as a trigger of autoimmune disease. Autoimmun Rev 7: 209-213.

3. Priyadarshini S, Palok A (2012) Effects of psychological stress on innate immunity and metabolism in humans: A systematic analysis. Plos One 7(9): 8-15.

4. Shrihari TG (2018) Chronic psychological stress induced microbial imbalance (dysbiosis) mediated autoimmune disease-A current concept. Gerontology and geriatric studies 3(1): 1 .

5. Shrihari TG (2017) Quantum healing - A novel current concept of holistic healing. International journal of complementary and alternative medicine 10(2): 329 .

ISSN: 2574-1241

DOI: 10.26717/BJSTR.2018.08.001667

Shrihari TG. Biomed J Sci \& Tech Res

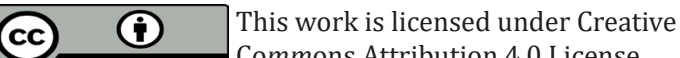

Submission Link: https://biomedres.us/submit-manuscript.php
6. Shrihari TG (2018) Endorphins- A novel hidden magic holistic healer. Journal of clinical and cellular immunology 9(2): 547-552.

7. Shrihari TG (2018) Endorphins- A forgotten hidden magic holistic healer: Minireview. Advanced complement and alternative medicine 2(5): $1-4$.

8. Shrihari TG (2018) Beta-Endorphins-A novel natural holistic healer. Journal of microbial and biochemical technology 10(2): 10-14.

9. IwaszkiewicZ KS, Schneider JJ, Hua S (2013) Targeting peripheral opioid receptors to promote analgesic and anti-inflammatory actions. Front pharmacol 24(4): 132-137.

10. Hua S (2016) Neuroimmune interaction in the regulation of peripheral opioid mediated analgesia in inflammation. Front immunol 2(7): 293298.

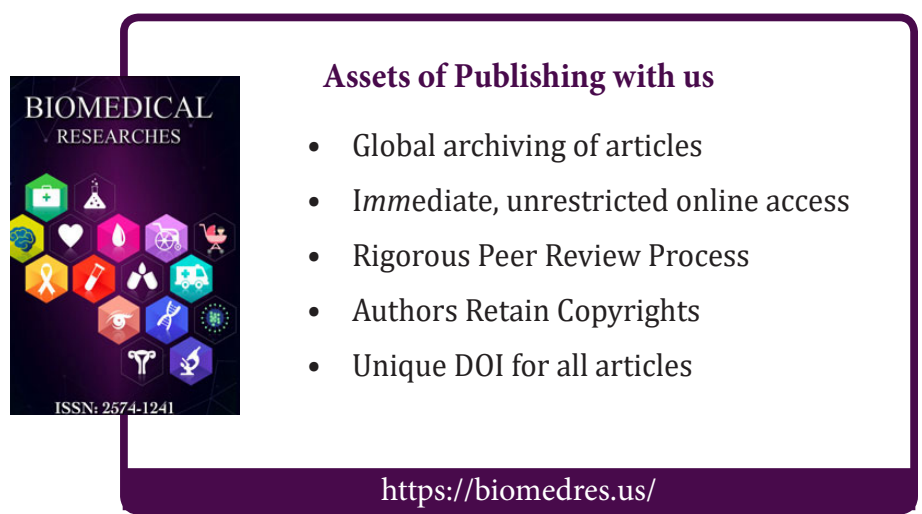

